\title{
Public Private Partnership
}

Richard O. Binswanger

Korrespondenz:

Dr. med. Richard O. Binswanger Radiologie und Nuklearmedizin FMH

Führungsschule Bodensee

Münsterlingen

Oberer Seeweg 9

CH-8597 Landschlacht

r.binswanger@bluewin.ch

www.fsb-spital.ch
Am 14. Juli 2010 beschloss die Delegiertenversammlung des Limmattalspitals, eine Public Private Partnership (PPP) einzugehen mit einer Privatfirma [1, 2]. Diese soll die operative Führung und den Betrieb der ambulanten Dienstleistung übernehmen. Ausserdem soll sie grosse Bauvorhaben vorbereiten, die eine Totalunternehmung bauen und unterhalten wird. Das Spital soll sich einmieten. Dieses Vorhaben wird hier weder positiv noch negativ beurteilt. Es werden lediglich Überlegungen dazu angestellt.

\section{Was ist Public Private Partnership?}

Als Public Private Partnership wird die Mobilisierung privaten Kapitals und Fachwissens zur Erfüllung staatlicher Aufgaben bezeichnet. PPP geht in vielen Fällen mit einer Teilprivatisierung von öffentlichen Aufgaben einher. Im Unterschied zur materiellen Privatisierung lässt der Staat eine bislang öffentlich wahrgenommene Aufgabe also nur teilweise los. Er zieht private Wirtschaftssubjekte lediglich hinzu. Die hoheitliche Erfüllungsverantwortung bleibt unangetastet [3]. Die Verträge laufen jahrzehntelang, typischerweise 30 Jahre.

\section{Und was steht dahinter?}

PPP wird in erster Linie zur Beschaffung von privatem Kapital für grosse Investitionen angestrebt, wenn der öffentliche Träger dieses nicht (rechtzeitig) zur Verfügung stellt [4]. Im Spital Limmattal geht es genau darum, nämlich um die Finanzierung der baulichen Totalsanierung. Der Input von Fachwissen steht im Rahmen einer PPP im Vergleich zur Kapitalbeschaffung meist im Hintergrund.

\section{Was zu beachten ist}

PPP und Teilprivatisierung sind nicht prinzipiell abzulehnen. In vielen Fällen ist PPP aber der erste Schritt zur vollständigen Privatisierung [4]. Der private Partner muss einen Profit erwirtschaften. Und zwar aus dem erwarteten Effizienzgewinn. Ist letzterer nicht gross genug, fallen die Kosten auf den öffentlichen Träger zurück.

\section{Offene Fragen}

Ist das Spital bereit für eine jahrzehntelange vertragliche Bindung an einen privaten Partner? Ist dieser kompetent genug? Ist er solide finanziert? Ist er in der Lage, die Komplexität des Projekts zu meistern? Wer kontrolliert ihn? Garantiert er eine erstklassige Medizin, auch langfristig? Wie stellt er sich zu «patient comes first» [5]? Wie ist das abgesichert? Wie steht es mit der ärztlichen Führerschaft (physician leadership)

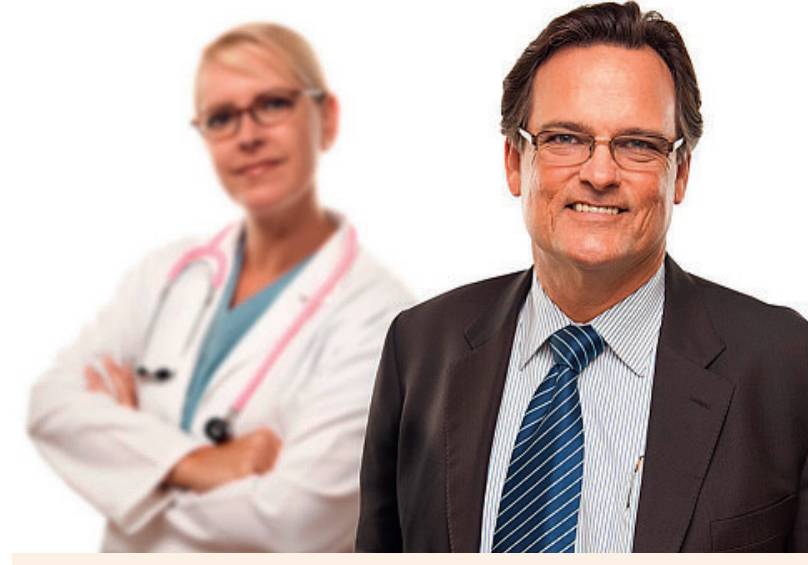

Public Private Partnership dient in erster Linie der Beschaffung privaten Kapitals für staatliche Aufgaben. Bei Spitälern muss die Frage erlaubt sein, ob genügend Ärzte in den Entscheidungsgremien vertreten sind.

unter den neuen Bedingungen [6, 7]? Sind genügend Ärzte in den Entscheidungsgremien vertreten? Was passiert, wenn der private Partner versagt? Sind die Ausstiegs- und Heimfallbedingungen genügend klar definiert? Bleibt die hoheitliche Erfüllungsverantwortung wirklich unangetastet? Diese Aufzählung ist keineswegs abschliessend.

\section{Fazit}

Public Private Partnership stellt dem öffentlichen Partner in erster Linie Kapital für grosse Investitionen zur Verfügung. Solche Projekte sind sehr langfristig, äusserst komplex und in ihrem Ausgang ungewiss. Meistens leiten sie die völlige Privatisierung ein. Auch wenn dies alles gewollt ist und in Kauf genommen wird. Den Vertragsbedingungen ist höchste Aufmerksamkeit zu widmen. Der Vollzug verlangt die entscheidende Mitwirkung der und Kontrolle durch die betroffene Ärzteschaft.

\section{Literatur}

1 Neue Zürcher Zeitung 16. 7.2010.

2 www.hservices.ch

3 Wikipedia.

4 Neubauer G. München. Gesundheitspiazza 2010.

5 Binswanger RO. Nutzen schaffen für Patienten. Schweiz Ärztezeitung. 2010; 91(11):470.

6 Binswanger RO. Ärztliche Führung. Schweiz Ärztezeitung. 2010; 91(21):835

7 Berry LL, Selterman KD. Management Lessons from Mayo Clinic. McGraw-Hill; 2008. 